\title{
Microsurgical resection of brain arteriovenous malformations in the elderly: outcomes analysis and risk stratification
}

\author{
Jan-Karl Burkhardt, MD, George F. Lasker, MD, PhD, Ethan A. Winkler, MD, PhD, Helen Kim, PhD, \\ and Michael T. Lawton, MD
}

Department of Neurological Surgery, University of California, San Francisco, California

\begin{abstract}
OBJECTIVE Few outcomes studies have been published on microsurgical resection of arteriovenous malformations (AVMs) in elderly patients, and most are limited by a small sample size and the heterogeneous application of treatment modalities. This study aimed to determine whether functional outcomes at last follow-up (LFU) in patients 60 years or older differed when stratified by age.

METHODS Patients 60 years or older $(n=104)$ who had undergone microsurgical AVM resection (total, $n=72 ; 60-65$ years, $n=35$; and $>65$ years, $n=37$ ) or observation $(n=32)$ were identified from a prospective database. Age, sex, Spetzler-Martin (SM) grade, supplemented SM grade, clinical presentation, AVM location, AVM-associated aneurysms, and functional outcome measured using the modified Rankin Scale (mRS score 0-2 [favorable] vs mRS score > 2 [unfavorable]) at LFU were analyzed.
\end{abstract}

RESULTS AVM patients undergoing microsurgical resection were younger, had lower AVM grades, and were more likely to present with rupture. Overall outcome in the surgical group was favorable in $71 \%$ of the patients and was statistically significantly better in patients $60-65$ years old $(p=0.039)$. In patients older than 65 years, outcome was dependent on SM grade and level of preexisting functional dependence. Patients with supplemented SM grades of greater than 6 points had favorable outcomes that were age dependent $(p=0.029)$. This difference was not observed in patients with lower supplemented SM grades or in those with low or high preoperative SM grades (SM grade $\leq 2$ and grade $\geq 4$, respectively).

CONCLUSIONS This study demonstrates that favorable outcomes can be achieved with microsurgical resection of AVMs in elderly patients, with careful patient selection. Outcomes in more elderly patients ( $>65$ years of age) are more dependent on preoperative SM and supplemented SM grading than those in younger cohorts.

https://thejns.org/doi/abs/10.3171/2017.6.JNS17392

KEY WORDS arteriovenous malformation; microsurgical resection; elderly; Spetzler-Martin grading system; Lawton-Young grading system; supplemented Spetzler-Martin grading; vascular disorders

$\mathrm{B}$ RAIN arteriovenous malformations (AVMs) are rare lesions (1.1-1.4 per 100,000 population) with aberrant communications between arteries and veins without intervening capillary beds, resulting in high-flow, high-pressure shunting. ${ }^{1-3}$ The lack of smooth muscle in the arterial microcirculation and deficiency of the internal elastic lamina in the venous component may contribute to rupture and intracranial hemorrhage through the weakened vascular wall. ${ }^{3}$ The 10 -year AVM rupture rate is approximately $30 \%$ (or $2 \%-4 \%$ per year). ${ }^{1,2,7,22}$ Whether
AVM formation is an embryological or developmental anomaly is a matter of debate. However, the majority of patients with AVMs are not diagnosed until they are 40 years of age and present with hemorrhage. ${ }^{6}$ Microsurgical resection offers definitive protection against hemorrhage by removing the arteriovenous pathology, and grading scales have been developed to predict surgical risk. Several reports have analyzed surgical risk and outcomes in patients older than 60 years and documented an increased risk-benefit relationship and a decreased surgical frequen-

ABBREVIATIONS AVM = arteriovenous malformation; $L F U=$ last follow-up; $m R S=$ modified Rankin Scale; $S M=$ Spetzler-Martin .

SUBMITTED February 13, 2017. ACCEPTED June 19, 2017.

INCLUDE WHEN CITING Published online December 22, 2017; DOI: 10.3171/2017.6.JNS17392. 
cy in the elderly. ${ }^{11,12,17-20}$ The Lawton-Young grading scale includes patient age as a component in the determination of operative risk, with patients stratified into age ranges of younger than $20,20-40$, and older than 40 years. ${ }^{8}$ When the Lawton-Young grade is added to the Spetzler-Martin (SM) grade, a supplemented SM grade ${ }^{11}$ also incorporates patient age in surgical risk prediction.

The limited number of studies investigating surgical outcomes in elderly patients $s^{4,10,16,21}$ is confounded by small sample sizes and/or heterogeneous application of treatment modalities (endovascular embolization, preoperative embolization, microsurgical resection, and radiosurgery). The aging population and refinement of neuroimaging modalities have led to higher AVM detection rates in patients older than 60 years. Additional analysis of surgical outcomes is needed to better guide management decisions and treatment allocation in elderly patients with AVMs. In this work, we present a prospectively derived, retrospective analysis of microsurgical outcomes after AVM resection in elderly patients, specifically comparing results in patients 60-65 years of age with those in patients older than 65 years.

\section{Methods \\ Study Design}

This study was approved by the institutional review board and performed in compliance with Health Insurance Portability and Accountability Act (HIPAA) regulations. Prior to enrollment, patients signed written consent to participate in this study. Patients 60 years or older who, between June 1997 and June 2016, had undergone resection of AVMs or observation without treatment were identified from a single-institution, prospectively maintained database. Demographic information, SM grade, LawtonYoung grade, supplemented SM grade, clinical presentation, hemorrhage rate before surgery, AVM location, AVM-associated aneurysms, and outcomes measured using the modified Rankin Scale (mRS score 0-2 [favorable] vs $\mathrm{mRS}$ score $>2$ [unfavorable]) were collected from the database. A neurologist or trained study coordinator performed patient outcome evaluations during postoperative clinic visits. Patients missing supplemented SM scores or surgical outcome information were excluded from the analysis. A detailed review of the literature (MEDLINE/ PubMed search) was also performed to identify all studies with more than 10 patients harboring AVMs that were surgically treated and/or observed.

\section{Patient Groups}

A total of 104 AVM patients who were 60 years or older at the time of surgical intervention or inclusion into the observation database were identified. When stratified by treatment group, 72 patients underwent resection, and 32 patients were observed without treatment. All patients had a follow-up clinical assessment of functional outcome. Surgical patients were further stratified into 2 age groups: $60-65$ years $(\mathrm{n}=35)$ and older than 65 years $(\mathrm{n}$ $=37$ ) for outcomes analysis as previously described. ${ }^{14,15}$ In our patient cohort, nearly half of the patients were between 60 and 65 years old and nearly half were older than 65 years.

\section{Statistical Analysis}

Statistical analysis was performed using IBM SPSS (version 22, IBM Corp.) and figures were generated using Excel (version 14.6, Microsoft Corp.). Continuous variables are presented as mean $\pm \mathrm{SD}$. Comparisons between groups were performed using the Mann-Whitney U-test for continuous parameters and the chi-square test or the Fisher's exact test for categorical parameters. Statistical significance was set at $\mathrm{p} \leq 0.05$.

\section{Results \\ Overall Results}

Clinical and radiological characteristics in patients undergoing resection of their AVM $(n=72)$ were significantly different from those in observed patients $(n=32$; Table 1). Patients undergoing resection were younger ( $\mathrm{p}$ $=0.048)$. Observed patients were more likely to present with incidental, unruptured AVMs ( $p<0.0001)$, and AVM patients who underwent surgery were more likely to present with ruptured AVMs $(\mathrm{p}=0.004)$. Eloquent AVM location was more common in observed AVM patients $(\mathrm{p}$ $=0.011)$. Both SM and Lawton-Young grades were lower in patients who underwent resection $(\mathrm{p}=0.002$ and $\mathrm{p}=$ 0.01 , respectively). With this selection bias, favorable outcome was comparable between patients with resected and observed AVMs at last follow-up (LFU; Table 2). However, the mean follow-up time was significantly shorter for surgical patients (20.2 months [SD 17.8]) than for patients undergoing observation (49.6 months [SD 39.1], $\mathrm{p}=0.001$ ).

\section{Resection Group}

The 72 patients undergoing AVM resection had a mean age of 66 years (range 60-90 years), with a mean age of 62 years in the 60- to 65-year-old group and 70 years in the 66- to 90-year-old group. There was no statistically significant difference between the 2 age groups in terms of sex, hemorrhagic presentation, AVM size, SM grade, LawtonYoung grade, supplementary SM grade, AVM location, or AVM-associated aneurysms (Table 1). The majority of AVMs in this analysis were smaller than $3 \mathrm{~cm}(47 / 72,65 \%)$ and rupture was the most common presentation in both age groups $(35 / 72,49 \%)$ (Table 1$)$. The $\mathrm{mRS}$ score prior to surgery was also equivalent between the groups (Fig. 1).

Outcome at LFU was favorable (mRS score 0-2) in a total of $71 \%(51 / 72)$ of patients, with a mean follow-up time of 20.2 months (Table 2 and Fig. 1). There was no significant difference in follow-up time between the 2 age groups $(p=0.37)$. Patients $60-65$ years of age had significantly better clinical outcomes at LFU than patients older than 65 years ( $83 \%$ vs $60 \%$ of patients with an mRS score $0-2, p=0.039$; Table 2 and Fig. 1).

Perioperative complications and reoperations were comparable between age groups (Table 3). Three patients (9\%) from the 60- to 65-year age group and 2 patients $(5 \%)$ from the older group required reoperation (Table 3). Review of the literature showed favorable outcomes in surgically treated elderly AVM patients and in those observed (Table 4). However, 2 studies comparing AVM surgery with natural history in the elderly showed more favorable outcomes in the surgical patients (Table 4). 
TABLE 1. Clinical and radiological characteristics of patients with resected or observed AVMs

\begin{tabular}{|c|c|c|c|c|c|c|}
\hline \multirow[b]{2}{*}{ Variable } & \multicolumn{4}{|c|}{ Resection } & \multicolumn{2}{|c|}{ Observation } \\
\hline & Total & $60-65$ Yrs & $>65$ Yrs & p Value* & Total & $\mathrm{p}$ Value \\
\hline No. of patients & 72 & 35 & 37 & & 32 & \\
\hline Sex, n (\%) & & & & 0.1 & & 0.67 \\
\hline Male & $42(58)$ & $24(69)$ & $18(49)$ & & $17(53)$ & \\
\hline Female & $30(42)$ & $11(31)$ & $19(51)$ & & $15(47)$ & \\
\hline Age in yrs & & & & $<0.0001$ & & 0.048 \\
\hline Mean (SD) & $66(5.5)$ & $62(1.8)$ & $70(5.1)$ & & $70(7.9)$ & \\
\hline Range & $60-90$ & $60-65$ & $66-90$ & & $61-86$ & \\
\hline Clinical presentation, $\mathrm{n}(\%)$ & & & & 0.36 & & $<0.0001$ \\
\hline Seizure & $9(12)$ & $5(14)$ & $4(11)$ & & $5(16)$ & \\
\hline Headache & $12(17)$ & $7(20)$ & $5(14)$ & & $1(3)$ & \\
\hline Neurological deficits & $2(3)$ & $2(6)$ & $0(0)$ & & $1(3)$ & \\
\hline Incidental & $6(8)$ & $3(9)$ & $3(8)$ & & $19(59)$ & \\
\hline Other & $8(11)$ & $4(11)$ & $4(10)$ & & $0(0)$ & \\
\hline Hemorrhage, n (\%) & $35(49)$ & $14(40)$ & $21(57)$ & 0.17 & $6(19)$ & 0.004 \\
\hline AVM size in $\mathrm{cm}$ & & & & 0.54 & & 0.10 \\
\hline Mean (SD) & $2.5(1.5)$ & $2.2(1.1)$ & $2.7(1.9)$ & & $3.1(1.9)$ & \\
\hline Range & $0.3-9.4$ & $0.3-4.1$ & $0.4-9.4$ & & $0.6-0.7$ & \\
\hline Size in $\mathrm{cm}, \mathrm{n}(\%)$ & & & & 0.51 & & 0.07 \\
\hline$<3$ & $47(65)$ & $23(66)$ & $24(65)$ & & $15(47)$ & \\
\hline $3-6$ & $22(31)$ & $12(34)$ & $10(27)$ & & $14(44)$ & \\
\hline$>6$ & $3(4)$ & $0(0)$ & $3(8)$ & & $3(9)$ & \\
\hline Deep venous drainage, $\mathrm{n}(\%)$ & $28(39)$ & $15(43)$ & $13(35)$ & 0.63 & $17(53)$ & 0.19 \\
\hline Eloquence, $\mathrm{n}(\%)$ & $32(44)$ & $16(46)$ & $16(43)$ & 0.1 & $23(72)$ & 0.011 \\
\hline SM grade, $\mathrm{n}(\%)$ & & & & 0.95 & & 0.002 \\
\hline 1 & $15(21)$ & $5(14)$ & $10(27)$ & & $5(16)$ & \\
\hline ॥ & $31(43)$ & $18(52)$ & $13(35)$ & & $5(16)$ & \\
\hline III & $21(29)$ & $11(31)$ & $10(27)$ & & $12(38)$ & \\
\hline IV & $4(6)$ & $1(3)$ & $3(8)$ & & $8(24)$ & \\
\hline V & $1(1)$ & $0(0)$ & $1(3)$ & & $2(6)$ & \\
\hline Nidus compact, $\mathrm{n}(\%)$ & $54(75)$ & $26(74)$ & $28(76)$ & 0.1 & $23(72)$ & 0.65 \\
\hline Associated aneurysms, $\mathrm{n}(\%)$ & $26(36)$ & $9(26)$ & $17(46)$ & 0.14 & $9(28)$ & 0.40 \\
\hline Infratentorial location, n (\%) & $20(28)$ & $8(23)$ & $12(32)$ & 0.44 & $7(22)$ & 0.53 \\
\hline $\begin{array}{l}\text { Lawton-Young supplementary } \\
\text { grade, } \mathrm{n}(\%)\end{array}$ & & & & 0.63 & & 0.01 \\
\hline III & $25(35)$ & $12(34)$ & $13(35)$ & & $3(9)$ & \\
\hline IV & $41(57)$ & $19(54)$ & $22(60)$ & & $24(75)$ & \\
\hline V & $6(8)$ & $4(12)$ & $2(5)$ & & $5(16)$ & \\
\hline
\end{tabular}

\section{Surgical Outcomes Stratified by Age Groups}

In the younger age group, outcomes were not dependent on SM or supplemented SM grade prior to surgery (Fig. 2). However, in patients older than 65 years, outcome was statistically significantly dependent on preoperative SM and supplemented SM grades (Fig. 2). When patients were grouped into different SM and supplemented SM groups, patients 60-65 years of age with a supplemented SM grade higher than 6 had favorable outcomes (9/10,
$90 \%)$ compared with patients older than 65 years $(5 / 13$, $38 \%)(p=0.029)$. This difference was not observed in lower supplemented SM grades or in both low and high SM grades (Table 2).

\section{Discussion}

This report is the largest study to date analyzing outcomes for the microsurgical resection of AVMs in the elderly, and it demonstrates overall favorable outcomes, as 
TABLE 2. Clinical outcome of patients with resected or observed AVMs based on SM and supplemented SM grades

\begin{tabular}{|c|c|c|c|c|c|c|}
\hline \multirow[b]{2}{*}{ Outcome* } & \multicolumn{4}{|c|}{ Resection } & \multicolumn{2}{|c|}{ Observation } \\
\hline & Total & $60-65$ Yrs & $>65 \mathrm{Yrs}$ & $\mathrm{p}$ Value $†$ & Total & p Valuef \\
\hline No. of patients & 72 & 35 & 37 & & 32 & \\
\hline All SM grades & & & & 0.039 & & 0.14 \\
\hline mRS scores 0-2 & $51(71)$ & $29(83)$ & $22(60)$ & & $27(84)$ & \\
\hline mRS scores 3-6 & $21(29)$ & $6(17)$ & $15(40)$ & & $5(16)$ & \\
\hline SM grade $\leq \|$ & & & & 0.49 & & 0.34 \\
\hline mRS scores 0-2 & $35(76)$ & $19(83)$ & $16(70)$ & & $9(90)$ & \\
\hline mRS scores 3-6 & $11(24)$ & $4(17)$ & $7(30)$ & & $1(10)$ & \\
\hline SM grade $\geq 111$ & & & & 0.05 & & 0.13 \\
\hline mRS scores 0-2 & $16(62)$ & $10(83)$ & $6(43)$ & & $18(81)$ & \\
\hline mRS scores 3-6 & $10(38)$ & $2(17)$ & $8(57)$ & & $4(19)$ & \\
\hline Supplemented SM grade $\leq 6$ & & & & 0.52 & & 0.66 \\
\hline mRS scores 0-2 & $35(76)$ & $20(80)$ & $17(71)$ & & $9(81)$ & \\
\hline mRS scores 3-6 & $12(24)$ & $5(20)$ & $7(29)$ & & $2(19)$ & \\
\hline Supplemented SM grade $\geq 7$ & & & & 0.029 & & 0.07 \\
\hline mRS scores 0-2 & $14(61)$ & $9(90)$ & $5(38)$ & & $18(86)$ & \\
\hline mRS scores 3-6 & $9(39)$ & $1(10)$ & $8(62)$ & & $3(14)$ & \\
\hline $\begin{array}{l}\text { Values are presented as the num } \\
* \text { The mRS scores are those at } \\
\text { months (SD } 39.1 \text { months) for tho } \\
\dagger \text { Comparison of age groups. } \\
\ddagger \text { Comparison of surgical treatm }\end{array}$ & $\begin{array}{l}\text { of patient } \\
\text { The mea } \\
\text { ho were c } \\
\text { versus ob }\end{array}$ & $\begin{array}{l}\text { Inless stated } \\
\text { for patients } \\
\text { d }(p=0.001)\end{array}$ & $\begin{array}{l}\text { vise. Boldfa } \\
\text { derwent re }\end{array}$ & $\begin{array}{l}\text { e indicates } \\
\text { I was } 20.2\end{array}$ & $\begin{array}{l}\text { ificance. } \\
7.8 \text { month }\end{array}$ & rsus 49.6 \\
\hline
\end{tabular}

assessed by mRS scores. Although good outcomes were observed in $71 \%$ of patients undergoing resection, the benefit was significantly better in patients 60-65 years of age (83\%) than in patients older than 65 years $(60 \%, \mathrm{p}=0.039)$.

With respect to the natural history of brain AVMs, several early works suggested that bleeding risk decreases with patient age, particularly after a patient reaches the age of 40 years. ${ }^{5,13}$ This notion was challenged by Crawford et al. when they reported a higher likelihood of hemorrhage in patients diagnosed with AVMs at an older age ( $89 \%$ risk of hemorrhage over 8 years in patients diagnosed after the age of 60 years vs $15 \%$ risk of hemorrhage in patients diagnosed between 20 and 29 years of age). ${ }^{2}$ A recently completed large-scale, multicenter, individual patient meta-analysis of 2525 patients with 6074 patientyears of follow-up demonstrated that increasing age and hemorrhagic presentation were significant predictors of subsequent hemorrhage in the untreated course of AVM patients. ${ }^{9}$ A recently published single-center, retrospective review of 28 AVM patients older than 65 years also demonstrated hemorrhage as the most common symptom of patients on presentation. ${ }^{16}$ This was confirmed in our analysis, with rupture observed in $49 \%$ of patients older than 60 years.

Lanzino et al. were the first investigators to examine outcomes in elderly patients after AVM resection. In their case series, 13 patients initially presented with intraparenchymal hemorrhage following AVM rupture. The mean follow-up time was 46 months across the subgroup. Of the 8 surviving patients, 6 regained independence in activities of daily living, 1 patient was described as independent with supervision, and the remaining patient was lost to follow-up. The authors concluded that age should not be a prohibitive factor for neurosurgical intervention in otherwise healthy patients presenting with ruptured AVMs. ${ }^{10}$ We confirmed this overall benefit of surgical intervention, with favorable mRS scores observed in $70 \%$ of our elderly cohort at LFU.

Hashimoto et al. published their experience following AVM resection over a 14-year period that included 32 patients older than 60 years. ${ }^{4}$ Twenty-three patients underwent microsurgical resection, 4 patients underwent radiosurgical treatment, and the remaining 5 patients were observed. Good to excellent outcomes were achieved in $69.6 \%$ of the elderly group after surgery or radiosurgery. In subgroup analysis, outcomes of patients with SM Grade I and II AVMs improved significantly following surgery. In patients with SM Grade III or higher AVMs on presentation, no benefit was observed. The authors concluded that surgical intervention is beneficial in elderly patients

TABLE 3. Perioperative complications of AVM patients stratified by age

\begin{tabular}{lcccc}
\hline \multicolumn{1}{c}{ Characteristic } & Total & $60-65$ Yrs & $>65$ Yrs & p Value \\
\hline No. of patients & 72 & 35 & 37 & \\
\hline Postop ICH, $\mathrm{n}(\%)$ & $7(10)$ & $3(9)$ & $4(11)$ & 0.75 \\
\hline Reop, $\mathrm{n}(\%)$ & & & & \\
\hline$\quad$ Postop ICH/AVM residual & $3(4)$ & $2(6)$ & $1(3)$ & 0.53 \\
\hline Wound infection & $1(1)$ & $1(3)$ & $0(0)$ & 0.30 \\
\hline VP shunt for hydrocephalus & $1(1)$ & $0(0)$ & $1(3)$ & 0.33 \\
\hline
\end{tabular}

$\mathrm{ICH}=$ intracerebral hemorrhage; $\mathrm{VP}=$ ventriculoperitoneal. 


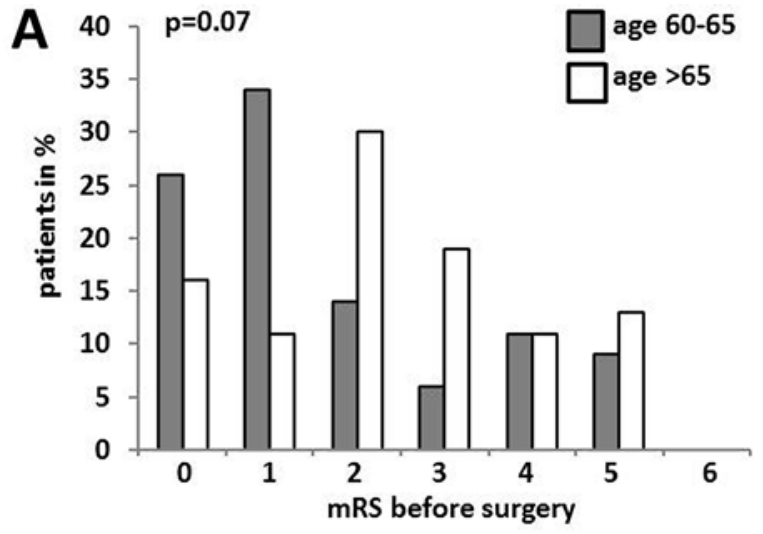

C $\square$ favorable clinical status (mRS 0-2) before surgery gain of favorable outcome (mRS 0-2) at LFU

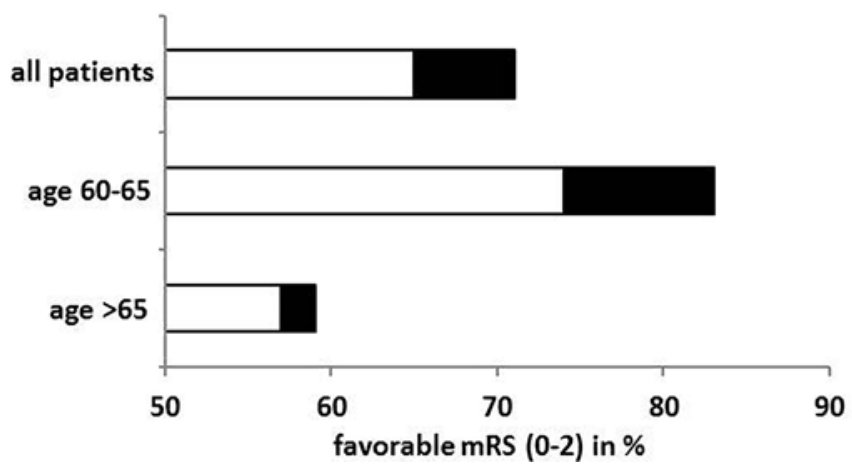

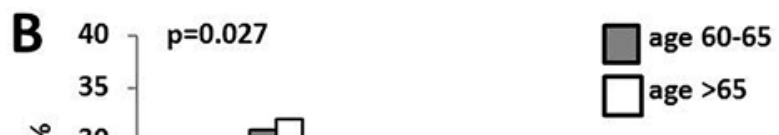
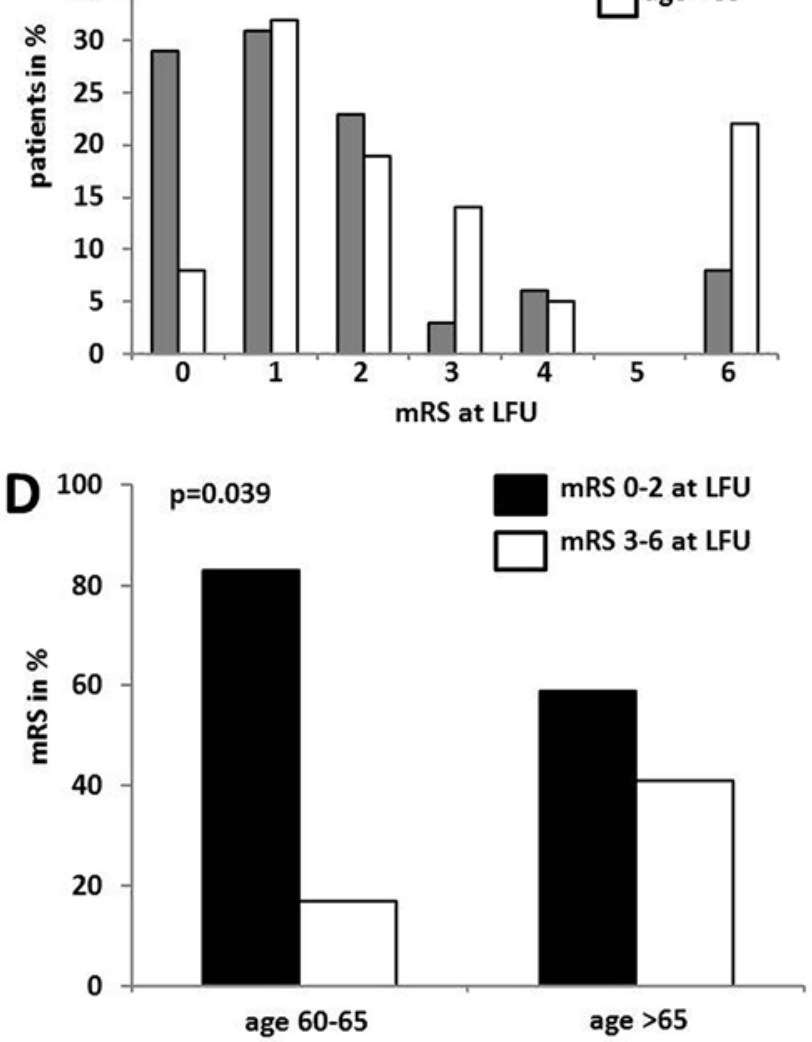

FIG. 1. Bar graph showing that the $m R S$ scores in both patient age groups were comparable before surgery $(p=0.07)(\mathbf{A})$, with a significantly better mRS score at LFU for those 60-65 years (B). Both groups gained more favorable outcomes (mRS scores 0-2) after surgery (C). Favorable outcome (dichotomized as mRS scores $0-2$ vs 3-6) was significantly higher in patients $60-65$ years (D).

with low-grade AVMs (i.e., SM Grade I or II AVMs) on presentation, and the role of surgery in patients older than 60 years with higher-grade AVMs needed further clarification. Our data help clarify the role of AVM grade on outcomes, with the effects of higher SM and supplemental
SM grades becoming more significant in more elderly patients, 65 years and older. Another interesting finding of the study by Hashimoto et al. was that all AVMs detected in elderly patients were smaller than $4 \mathrm{~cm}$. The authors inferred that this may be attributed to the fact that larger

TABLE 4. Review of the literature comparing surgical treatment and observation in elderly patients with AVM

\begin{tabular}{|c|c|c|c|c|c|c|}
\hline \multirow[b]{2}{*}{ Authors \& Year } & \multirow{2}{*}{$\begin{array}{l}\text { Mean Age in } \\
\text { Yrs (range) }\end{array}$} & \multicolumn{2}{|c|}{ Observation } & \multicolumn{3}{|c|}{ Treatment } \\
\hline & & No. of Patients & mRS Scores 0-2 & No. of Patients & mRS Scores 0-2 (total) & mRS Scores 0-2 (surgery only) \\
\hline Pabaney et al., 2016 & $73(65-89)$ & 13 (4 LF) & $89 \%$ & 15 & $87 \%$ & $91 \%$ \\
\hline Tong et al., 2015 & $65(60-75)$ & 14 & $57 \%$ & 63 & $69 \%{ }^{*}$ & $78 \%$ \\
\hline Hashimoto et al., 2004 & $69(60-82)$ & 5 & $69 \% \dagger$ & 27 & $69 \% \dagger$ & NA \\
\hline Lanzino et al., 1997 & $67(61-87)$ & NA & NA & 13 & NA & $77 \%$ \\
\hline Nagata et al., 2006 & NA $(60-79)$ & 15 & NA $\ddagger$ & 18 & NA & $61 \% \ddagger$ \\
\hline Current study & $66(60-90)$ & 32 & $84 \%$ & 72 & NA & $71 \%$ \\
\hline \multicolumn{7}{|c|}{$\begin{array}{l}\text { LF = lost to follow-up; NA = not available. } \\
\text { * Total patient population including patients treated with microsurgery }(78 \% \mathrm{mRS} \text { score } 0-2) \text {, embolization alone }(50 \% \mathrm{mRS} \text { score } 0-2) \text {, stereotactic radiosurgery }(55 \% \\
\mathrm{mRS} \text { score } 0-2) \text {, and observation ( } 57 \% \mathrm{mRS} \text { score } 0-2) \text {. No separate outcome for the entire treatment group without observation was presented. } \\
\dagger \text { Five of } 32 \text { patients were observed only and did not undergo treatment. No separate outcome with or without treatment was presented. } \\
\text { † There was no information on LFU time for the observation group, although the rate of favorable mRS score at presentation was } 87 \% \text {. LFU for the treatment group was } \\
0-3 \text { months. }\end{array}$} \\
\hline
\end{tabular}



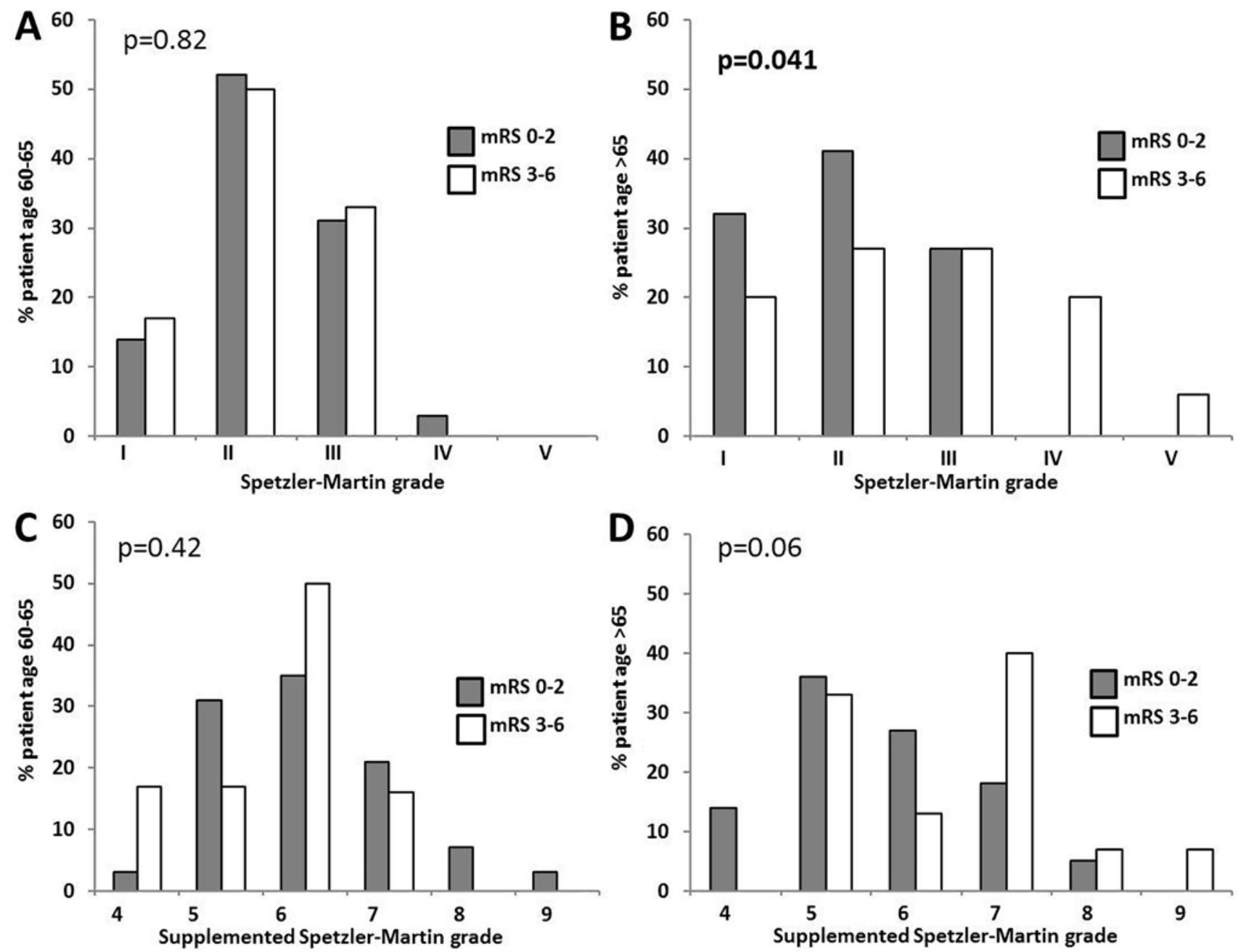

FIG. 2. Dichotomized outcome (favorable [mRS scores 0-2] vs unfavorable [mRS scores 3-6]) based on SM grade (A and B) and supplemented SM grade ( $C$ and $D)$ for patients $60-65$ years $(A$ and $C$ ) and those older than 65 years $(B$ and $D)$. Patients older than 65 years showed a significantly dependent outcome on SM grade $(p=0.041)$ and a borderline significantly dependent outcome on supplemented SM grade $(p=0.06)$.

AVMs are less likely to remain symptom free until a later age, and thus they would be diagnosed and treated earlier. ${ }^{4}$ In agreement with this hypothesis, AVMs smaller than 3 $\mathrm{cm}$ were the most frequently encountered $(65 \%$ of total AVMs) within our cohort of elderly patients.

Our study was limited by the lack of randomization between the resection group and the observation group. Surgical patients are a selected patient group; patients with lower SM AVM grades and hemorrhagic presentations were more likely to undergo resection than patients with incidental AVMs and higher SM AVM grades. With this selection bias, we achieved a high proportion of favorable outcomes in both the surgical and observed AVM patients, and there was no significant difference in outcome between the groups. This was confirmed by a systematic review of the literature (Table 4), which showed favorable outcome in AVM patients with or without surgical treatment. Our single-center experience warrants external validation. Due to this selection bias, an age- and risk factor-matched analysis of patients managed differently was not possible.

\section{Conclusions}

Although our study is limited by its retrospective analysis of a prospective data set and by a small sample size, it is still the largest surgical series in the literature on microsurgical results in elderly AVM patients and provides evidence that outcomes are favorable in patients 60-65 years of age. Outcomes in the group of patients older than 65 years are dependent on preoperative SM or supplemental SM grading. This analysis may be used to refine current perioperative predictors for elderly patients presenting with AVMs.

\section{Acknowledgments}

This research was supported in part by NIH grant no. R01 NS034949.

We thank Philippe Jolivalt for data management and Diana Guo and Keva DeKay for patient outcome assessments.

\section{References}

1. Abecassis IJ, Xu DS, Batjer HH, Bendok BR: Natural history 
of brain arteriovenous malformations: a systematic review. Neurosurg Focus 37(3):E7, 2014

2. Crawford PM, West CR, Chadwick DW, Shaw MD: Arteriovenous malformations of the brain: natural history in unoperated patients. J Neurol Neurosurg Psychiatry 49:1-10, 1986

3. Friedlander RM: Clinical practice. Arteriovenous malformations of the brain. N Engl J Med 356:2704-2712, 2007

4. Hashimoto H, Iida J, Kawaguchi S, Sakaki T: Clinical features and management of brain arteriovenous malformations in elderly patients. Acta Neurochir (Wien) 146:1091-1098, 2004

5. Heros RC, Tu YK: Is surgical therapy needed for unruptured arteriovenous malformations? Neurology 37:279-286, 1987

6. Hofmeister C, Stapf C, Hartmann A, Sciacca RR, Mansmann $\mathrm{U}$, terBrugge $\mathrm{K}$, et al: Demographic, morphological, and clinical characteristics of 1289 patients with brain arteriovenous malformation. Stroke 31:1307-1310, 2000

7. Itoyama Y, Uemura S, Ushio Y, Kuratsu J, Nonaka N, Wada $\mathrm{H}$, et al: Natural course of unoperated intracranial arteriovenous malformations: study of 50 cases. J Neurosurg 71:805809, 1989

8. Kim H, Abla AA, Nelson J, McCulloch CE, Bervini D, Morgan MK, et al: Validation of the supplemented Spetzler-Martin grading system for brain arteriovenous malformations in a multicenter cohort of 1009 surgical patients. Neurosurgery 76:25-32, 2015

9. Kim H, Al-Shahi Salman R, McCulloch CE, Stapf C, Young WL: Untreated brain arteriovenous malformation: patientlevel meta-analysis of hemorrhage predictors. Neurology 83:590-597, 2014

10. Lanzino G, Fergus AH, Jensen ME, Kongable GL, Kassell NF: Long-term outcome after surgical excision of parenchymal arteriovenous malformations in patients over 60 years of age. Surg Neurol 47:258-264, 1997

11. Lawton MT, Kim H, McCulloch CE, Mikhak B, Young WL: A supplementary grading scale for selecting patients with brain arteriovenous malformations for surgery. Neurosurgery 66:702-713, 2010

12. Luessenhop AJ, Gennarelli TA: Anatomical grading of supratentorial arteriovenous malformations for determining operability. Neurosurgery 1:30-35, 1977

13. Luessenhop AJ, Rosa L: Cerebral arteriovenous malformations. Indications for and results of surgery, and the role of intravascular techniques. J Neurosurg 60:14-22, 1984

14. Nagata S, Matsukado K, Natori Y, Sasaki T, Fukui M: Surgical indications for arteriovenous malformations in patients over the age of 60 years: retrospective analysis of 33 patients Br J Neurosurg 20:146-149, 2006
15. Orimo H: [Reviewing the definition of elderly.] Nippon Ronen Igakkai Zasshi 43:27-34, 2006 (Jpn)

16. Pabaney AH, Reinard KA, Kole MK, Seyfried DM, Malik GM: Management of arteriovenous malformations in the elderly: a single-center case series and analysis of outcomes. J Neurosurg 125:145-151, 2016

17. Shi YQ, Chen XC: A proposed scheme for grading intracranial arteriovenous malformations. J Neurosurg 65:484-489, 1986

18. Spears J, TerBrugge KG, Moosavian M, Montanera W, Willinsky RA, Wallace MC, et al: A discriminative prediction model of neurological outcome for patients undergoing surgery of brain arteriovenous malformations. Stroke 37:14571464, 2006

19. Spetzler RF, Martin NA: A proposed grading system for arteriovenous malformations. J Neurosurg 65:476-483, 1986

20. Spetzler RF, Ponce FA: A 3-tier classification of cerebral arteriovenous malformations. Clinical article. J Neurosurg 114:842-849, 2011

21. Tong X, Wu J, Lin F, Cao Y, Zhao Y, Ning B, et al: Brain arteriovenous malformations in elderly patients: clinical features and treatment outcome. Acta Neurochir (Wien) 157:1645-1654, 2015

22. Yamane F, Takeshita M, Izawa M, Kagawa M, Sato K, Takakura K: Natural history of arteriovenous malformations: analysis of non-radically treated patients. J Clin Neurosci 5 Suppl:26-29, 1998

\section{Disclosures}

The authors report no conflict of interest concerning the materials or methods used in this study or the findings specified in this paper.

\section{Author Contributions}

Conception and design: Lawton, Burkhardt. Acquisition of data: Lawton, Burkhardt, Lasker, Winkler. Analysis and interpretation of data: all authors. Drafting the article: Burkhardt, Lasker. Critically revising the article: all authors. Reviewed submitted version of manuscript: all authors. Approved the final version of the manuscript on behalf of all authors: Lawton. Statistical analysis: Burkhardt, Lasker, Kim. Study supervision: Lawton, Kim.

\section{Correspondence}

Michael T. Lawton, Department of Neurosurgery, Barrow Neurological Institute, 2910 N 3rd Ave., Phoenix, AZ 85013. email: michael.lawton@barrowbrainandspine.com. 